star at just the right distance for liquid water to exist. It is the most Earth-like planet found so far that could potentially host life.

A team led by Elisa Quintana of the SETI Institute in Mountain View, California, discovered the planet, Kepler-186f, by looking at data from NASA's Kepler space telescope. Slight drops in a star's brightness revealed the orbiting planet, the fifth known in that particular system.

Kepler-186f is just 1.1 times the size of Earth and orbits its star every 130 days. It is towards the outer edge of the star's habitable zone - in our Solar System, it would be equivalent to putting Earth out near the orbit of Mars.

Science 344, 277-280 (2014)

For a longer story on this research, see go.nature.com/tmbgje

MICROBIAL EVOLUTION

\section{How a flesh-eater evolved}

A deadly wave of flesh-eating bacteria emerged in the 1980 s when a single cell gained a pair of toxin genes from another bacterium.

Infections with group A Streptococcus (GAS) strains, which cause necrotizing fasciitis, spiked worldwide in the late 1980s and early 1990s. To piece together the sequence of molecular events behind this epidemic, James Musser at the Houston Methodist Research Institute in Texas and his team sequenced the genomes of 3,615 GAS strains isolated from Europe and North America between 1969 and 2013.

Analysis of the genomes revealed a series of genetic changes that began to occur in the early 1970 s. The final changes that took place before the strain became a voracious flesh-eater happened in around 1983, when lessvirulent strains acquired the genes that are needed to produce certain toxins in humans.

\section{Liquid bubbles stop sound}

Liquid foam can block the transmission of ultrasound, report Valentin Leroy at Paris Diderot University and his colleagues.

The French team created the foam by bubbling an insoluble gas, perfluorohexane, into water containing a surfactant, and then sent ultrasound through the foam.

The elastic, thin films at the edges of adjacent foam bubbles reflected the sound waves. The exact frequencies that were blocked varied with the average bubble size, the biggest of which measured up to 50 micrometres in radius.

The findings show that foams can act as acoustic metamaterials - materials that block sound waves because of their unique structure.

Phys. Rev. Lett. 112, 148307 (2014)

\section{MICROBIOLOGY}

\section{Bacteria elbow out the competition}

Some microorganisms push others out of the way to gain better access to oxygen.

Wook Kim and Kevin Foster at the University of Oxford, UK, studied the soil bacterium Pseudomonas fluorescens, which grows in dense layers called biofilms.

They found that a strain that consistently outgrew others and dominated the colony carried a mutation in a gene called $r s m E$. This mutant strain secretes polymers that expand, nudging neighbours aside and allowing cells to reach the colony surface where they can receive the most oxygen.

Life in tightly packed communities has selected for this bacterial pushiness, the authors say.

http://doi.org/sb5 (2014) SOCIAL SELECTION Rominaratiea

\title{
Illegal fishing hooks online attention
}

Researchers on Twitter were astounded by some of the figures given in a paper describing extensive illegal fish imports into the United States. According to Tony Pitcher at the University of British Columbia in Vancouver and his colleagues, in 2011 more than $20 \%$ of wild-caught seafood coming into the country - worth between US $\$ 1.3$ billion and $\$ 2.1$ billion - was from illegal or unreported fishing. To make their estimates, the researchers used data from the US National Marine Fisheries Service for 30 major seafood products from 10 countries. Illegal, unreported and unregulated fishing disrupts ecosystems, food security and livelihoods around the world, the authors say.

Mar. Policy 48, 102-113 (2014)

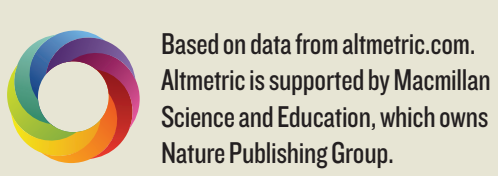

ONATURE.COM

For more on popular papers: go.nature.com/05v8cv

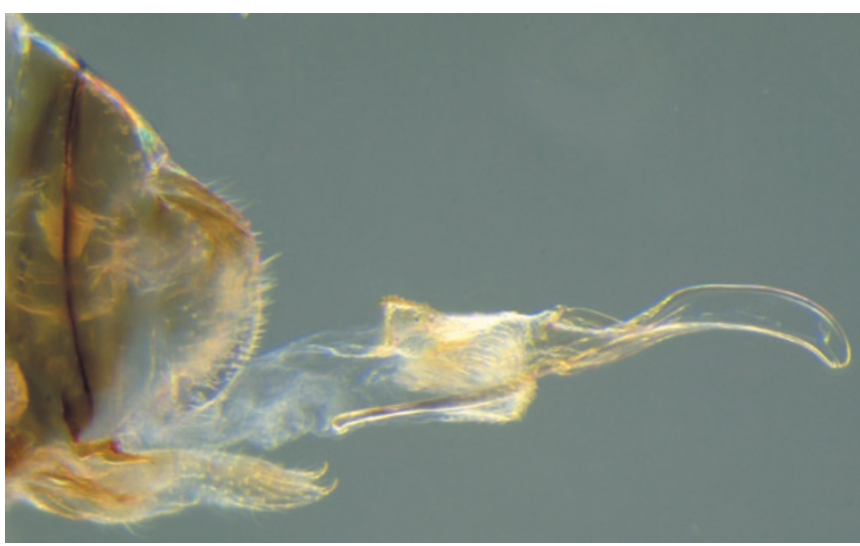

\section{ZOOLOGY}

\section{Sex changed in Brazilian insect}

Female insects in Brazilian caves initiate reproduction, and they do so with a penis.

Kazunori Yoshizawa at Hokkaido University in Sapporo, Japan, and his colleagues studied four Neotrogla species, one of which copulates for up to 70 hours. The authors found that the female uses an external organ (pictured) during sex to penetrate the male and to receive sperm for both reproduction and nutrition. All of the species have spines on the penis-like structure, which the females use to anchor themselves in the male genital chamber.

The competition between females for mates might have driven the evolution of this elaborate sexual structure, the authors say. However, this is the only known case of reversed sex organs in animals with reversed sexual roles, they add.

Curr. Biol. http://dx.doi. org/10.1016/j.cub.2014.03.022 (2014)

For a longer story on this research, see go.nature.com/ptnetb

\section{DNATURE.COM}

For the latest research published by Naturevisit:

www.nature.com/latestresearch 